\title{
Analysis of Hotel Management Problems and Countermeasures Based on Consumption Cycle
}

\author{
Shiying Yang, Mintian Li \\ Department of economic management, Hebei College of science and Technology, Baoding, Hebei, \\ 071000, China
}

Keywords: Consumption cycle, Hotel management, Problem, Countermeasure

\begin{abstract}
With continuous development of economic level and technical level in China, people's living quality improves significantly, and an increasing number of people go out for traveling. Rapid development of tourism offers an opportunity for development of China's hotel industry. Meanwhile, competitions of hotel enterprises also become fiercer and fiercer. To gain a position in cruel competition environment, hotels must boost their competitiveness and do hotel management well. In hotel management, consumption cycle theory is very important. Different types of consumption cycle will impose diverse impacts on hotel management work. So, hotels should carry out work under the background of consumption cycle in order to implement hotel management well. In this paper, the author deeply analyzes hotel management problems based on consumption cycle, sets forth the author's opinions and propose countermeasures, in the hope of offering help for doing well hotel management work.
\end{abstract}

\section{Introduction}

Tourism development drives development of hotel industry, but meanwhile hotel industry is confronted with severe challenges. People put forward higher and higher requirements for hotels. If hotels still adopt traditional management mode, they cannot meet customer's demands. Thus, hotels must change their management ideas and take innovative management mode in order to improve management level, attract more consumers and drive better development of hotels.

\section{Influence of consumption cycle on hotel management}

Consumption cycle analysis based on different consumer types. Different consumer types generate diverse effects on hotel consumption cycle. This paper analyzes six types of consumers as follows. 1) Retired workers. Such type of consumers has plenty of time, and their traveling time is not fixed. Besides, they own certain power of consumption. Such consumers generally choose travelling during non-holidays and non-festivals. 2) Teachers and students. The time of such consumer group is relatively fixed. They generally travel during winter and summer vacations, holidays and festivals. 3) Childless young people. Such consumers need to work, so they often travel during statutory holidays. 4) Children at the age of below 16. Such consumers generally go out for travelling with their parents. Their parents have to work, so they generally travel in holidays and festivals. The consumption peak of such consumers is lower than that of childless young people. 6) Comprehensiveness of hotels is strong. Hotels can not just meet accommodation demand, but also satisfy conference and banquet needs. Such characteristic attracts some units which need to rent a venue for academic exchange and meetings. So, the hotel is a good choice. Such type of consumers is relatively fixed ${ }^{[1]}$.

Influence of consumption cycle on hotel management. Different consumers own diverse consumption cycles, while diverse consumption cycles generate effects on hotel management. Consumption cycle will exert an influence on market competition degree. In mild competition stage, economic benefit of hotels is high, and employees can gain high remuneration. Hence, employees' working enthusiasm is high, and reward system is not required to stimulate employees. In fierce market competition environment, the business of hotels is not very good, so employees' salary is low. As a result, their working enthusiasm declines. At this time, hotel leaders must attach importance to talent management and retain employees through reward mechanism. 


\section{Hotel management problems based on consumption cycle}

Personnel management problems of hotels. Personnel management problems of hotels are mainly reflected in the following aspects. Firstly, performance management is not scientific. Hotel employees expect to gain anticipated salary. In actual work, if economic benefit of a hotel is not good, employees' salary will be low. Besides, unequal treatment may appear. If economic benefit of a hotel is high, employees' salary will also increase. In view of this, hotels should establish scientific and reasonable performance management system in performance management so as to mobilize employees' working enthusiasm. But in actual performance management, the problems of consistent emphasis and large gap in treatment among employees exist. When employees' salary is low, many employees will leave the hotel for gaining economic benefit. Thus, hotel talents become fewer and fewer. Moreover, after hotels recruit new employees, they need an adaptive phase. Meanwhile, they will trigger various problems because they cannot well cognize hotel culture and management before they adapt hotel working environment.

Safety management problems of hotel. With the growth in the living standard, the articles people take become increasingly valuable. Thus, hotels must implement well safety management. In the peak period, many people choose to live in hotels. In this stage, holes gain high economic benefit and meanwhile need to solve safety problem which happen frequently. Besides, everyone has his own characters, so many people have their unique demands. In such case, safety managements may happen easily between hotels and customers. In addition, some unexpected conflicts may happen among customers. All these increase the difficulty in carrying out conflict safety management. Some hotels are weak in handling emergencies, and thus cannot meet customers' demand. As a result, they lose some customers, and economic benefit of hotels decline. Safety problems also exist during off-peak period $^{[2]}$. In this stage, safety problems are mainly reflected in the following: employees' safety awareness declines; they pay no attention to safety management and fail to discover potential safety loopholes, thus leading to safety accidents.

Service quality problems of hotels. Currently, hotel management in China is seriously affected by bureaucracy theory. Thus, hotel work is often done by focusing on the posts in management process. In different periods, the ability of hotel management personnel to cope with emergencies is weak; services are not standard enough; service quality does not comply with standards. When hotels are in the off-peak period, the supply exceeds the demand. Such phenomenon causes the hotel cannot gain expected economic benefit, so employees' salary is affected. This to some extent affects employees' working phenomenon. In such circumstance, employees do not treat work seriously and service quality declines significantly. When service quality is unable to satisfy customers; demand, hotels will lose some customers. Further, this will affect long-term development of hotels and form a vicious circle. When hotels are in the peak period, since customers are numerous and the number of service personnel is limited, some negligence will occur inevitably and some details are ignored. As a result, service quality declines obviously.

Strategic management problems of hotels. To achieve long-term development, hotels should formulate scientific and rational development strategy, carry out management in line with scientific development strategy and promote hotel development. During formulating development strategy, hotels should take into account of consumption cycle theory, and combine actual operation situation of hotels so as to accurately analyze supply and demand of hotels. Hotel supply and demand situations are mainly classified into three types; 1 ) the supply is judged according to the demand in the highest-peak period; 2) the supply is judged according to the demand in the lowest-peak period; 3)

the supply is judged according to the demand in the highest-peak period and other peak period ${ }^{[3]}$. During carrying out statistic management, hotels fail to work according to the analysis of consumption cycle, but expand blindly, thus leading to the decrease in economic benefit. 


\section{Effective hotel management measures based on consumption cycle}

To carry out talent management well. Talent management occupies an important position in hotel management and exerts a great influence on long-term development o hotels. In view of this, it is quite necessary to improve talent management level and practically implement talent management. Employees are the subjects of executing hotel work. If hotels fail to effectively manage employees, hotel work will not be executed smoothly. Thus, hotel management personnel should establish talent management system in accordance with different periods of consumption cycle and carry out work according to the management system. In this way, hotels can get twofold results with half efforts. For example, in peak period, leaders may boost the performance indicator properly; in the off-peak period, the performance indicator may be reduced properly to narrow salary gap in different periods, ensure employees' working enthusiasm and make efforts to create more economic profits. Moreover, hotel management personnel can stimulate employees' working enthusiasm through establishing sound performance evaluation, reward and punishment mechanism. Managers may give proper economic reward to the employees with outstanding performance and properly punish the employees with poor working attitude. This can facilitate employees to work more actively. Only when employees work hard can economic benefit of hotels increase ${ }^{[4]}$.

To carry out safety management well. Safety management is an all-important constituent part of hotel management. To obtain sustainable development, it is very necessary for hotels to boost safety awareness of management personnel and employees and do safety management well. Hotels may increase invest in constructing safety facilities and then promote overall safety management level. In the peak period, it is necessary to train employees and let them know the possible dangers. In this way, employees can discover potential threats, solve them in time and ensure life safety of customers. In the off-peak period, although the number of customers is small, hotels should harbor the responsible attitude to every customer and train employees to improve their ability to handle contradictions. In the meantime, hotels should find out potential threats and propose effective measures. In this way, the problems can be solved in time when they happen so that the extent of hazard can be minimized.

To improve hotel service quality. Customers mainly consider service quality when they choose a hotel. If hotel service quality is superior, customers will continue to choose this hotel in future. If the service quality is poor, customers will no longer choose this hotel in future. Thus the hotel will gradually lose customers and affects its economic benefit. So, it is imperative to boost hotel service quality. Hotel management personnel need to organize personnel training to improve their comprehensive service ability. In the peak period, employees must complete service work in a superior and efficient manner. In the off-peak period, employees should focus on details while providing satisfying services, leave good impression on customers and then attract more customers.

To carry out strategic management well. Hotels need to formulate explicit development strategy in development process and carry out management according to the strategy, which can help hotels gain good results, in view of importance of strategic management, management personnel should pay more attention to strategic management, analyze consumption cycle in detail, cognize economic benefit in different stages according to the analysis result and then confirm hotel development strategy. Appropriate development strategy is bale to drive hotel development. Hence, the function of strategic management for long-term hotel development cannot be ignored ${ }^{[5]}$.

Hotel management based on consumption cycle analysis result. Applying consumption cycle analysis result in hotel management is a very effective move, which can promote hotel management level, practically implement management work and facilitate better development of hotels. Talent management, safety management, strategic management and service quality are very important constituent parts of hotel management. If the effects of consumption cycle on hotel management are overlooked, economic benefit of hotels will be low, and employee turnover is serious. Even hotels cannot operate normally. Thus, it is imperative to carry out hotel management based on consumption cycle analysis results. 


\section{Conclusion}

In conclusion, consumption cycle theory is all-important in hotel management. If the effects of consumption cycle on hotel management are ignored, the function of management work will not be fully exerted, and management effect is not significant. Meanwhile, hotels cannot gain better development. Therefore, in actual hotel management, hotel management analysis results must be considered. The effects of consumption cycle on hotel management can be gained in the analysis. Then, in actual management process, the problems may be extracted one by one, and effective measures may be adopted to solve them. Further, scientific and reasonable strategies can be made. Hotels may start from talent management, strategic management, safety management and service quality to manage hotels, give play to the functions of management, increase economic benefit and lay a good foundation for better development.

\section{References}

[1] Yang Shuyuan, On Hotel Management Problems and Effective Countermeasures Based on Consumption Cycle. Net Friend World Cloud Education, 2014(14):122-122.

[2] Chang Shujuan, Hotel Management Problems and Countermeasures Based on Consumption Cycle. Commercial Times, 2014(18):109-110.

[3] Yao Weiwei, Study on Hotel Management Mode under Low-carbon Tour Perspective. Productivity Research, 2012(5):203-204.

[4] Pi Pingfan, Huang Yan, Xiao Xuan et al., Research on Hotel Management Talent Training Mode Innovation Based on Professional Manager Goal Orientation. Value Engineering, 2014(27):267-269.

[5] Ge Li, Exploration of Innovative Development of Hotel Management in New Period. China Business \& Trade, 2014(21):111-111,112. 